\title{
Role of Glycerol Oxidation Pathways in the Reductive Acid Leaching Kinetics of Manganese Nodule Using Glycerol
}

Aishvarya Venkataseetharaman ${ }^{a, b, *, \Omega}$, Geetanjali Mishra ${ }^{b, \Omega}$, Malay Kumar Ghosh ${ }^{\text {a,b }}$ and Goutam Kumar Das , *

a Academy of Scientific and Innovative Research (AcSIR), CSIR-Institute of Minerals and Materials Technology Campus, Bhubaneswar, India-751013.

${ }^{b}$ Hydro \& Electrometallurgy Department, CSIR-Institute of Minerals and Materials Technology, Bhubaneswar, India-751013.

${ }^{c}$ CSIRO Mineral Resources, 7 Conlon Street, Waterford, Western Australia 6152

*Corresponding author1: aishvarya@immt.res.in , Phone: +91-7735849811

*Corresponding author2: Goutam.Das@csiro.au. Phone: +61 893348933 | Fax: +61 89334 8001

$\Omega$ Authors have made equal contribution to the work 


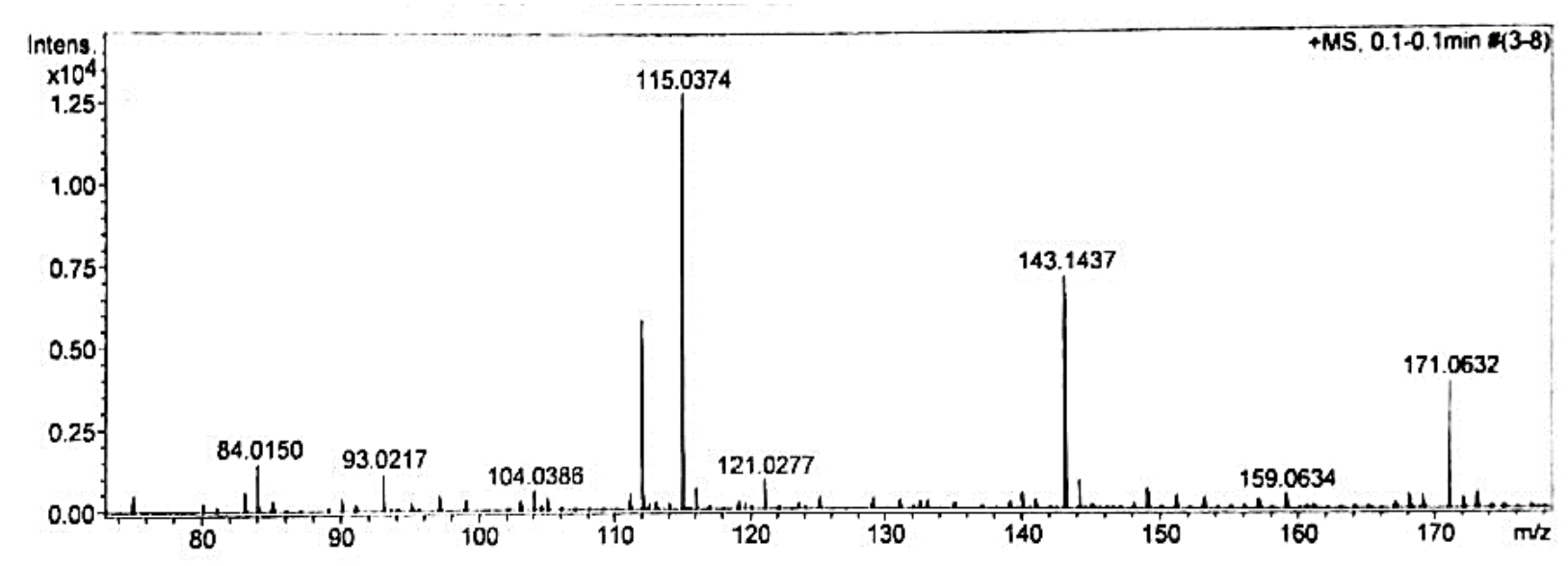

Figure. S1. Mass spectra of glycerol in water showing characteristic peaks of protonation at $\mathrm{m} / \mathrm{z} 93$ and with $\mathrm{Na}^{+}$ion at m/z 115. 